\title{
ChemComm
}

Cite this: Chem. Commun., 2013, 49, 5595

Received 16th March 2013, Accepted 29th April 2013

DOI: $10.1039 / c 3 c c 41965 g$

www.rsc.org/chemcomm

The facile synthesis of the first stable selenosilanoic acid-base adduct $\mathrm{LSi}$ (=Se)OH(dmap) 3 ( $\mathrm{L}=\mathrm{CH}[\mathrm{C}(\mathrm{Me}) \mathrm{NAr}]_{2}, \mathrm{Ar}=2,6-\mathrm{iPr}_{2} \mathrm{C}_{6} \mathrm{H}_{3}, \mathrm{dmap}=$ 4-dimethylaminopyridine), the heavier analogue of the thiosilanoic acid adduct $\mathrm{LSi}(=\mathrm{S}) \mathrm{OH}(\mathrm{dmap}) 1$, is reported. Both adducts 1 and 3 react readily with $\mathrm{MesCu}$ (Mes = 2,4,6-trimethylphenyl) to form the novel dimeric $\mathrm{Cu}(\mathrm{I})$ complexes $[\mathrm{LSi}(=\mathrm{E}) \mathrm{OCu}]_{2}(4: \mathrm{E}=\mathrm{S} ; 5: \mathrm{E}=\mathrm{Se})$ with unprecedented intermolecular $\mathrm{Si}=\mathrm{E} \rightarrow \mathrm{Cu}-\mathrm{O}-\mathrm{Si}$ coordination modes. The latter are efficient pre-catalysts for the $\mathrm{Cu}(1)$-mediated aziridination of styrene with $\mathrm{Phl}=\mathrm{N}(\mathrm{Ts})$ (Ts = tosyl).

Using organic molecular defined species containing $\mathrm{M}-\mathrm{O}-\mathrm{Si}$ moieties as structural models for silica-supported metal/metal oxide catalysts has been proved to be a facile method to unravel the structure of a pre-catalyst as well as the mechanism of a catalytic reaction. ${ }^{1}$ For example, the globular 56-membered copper(I) siloxane containing core made up of $\mathrm{Cu}-\mathrm{O}-\mathrm{Si}$ moieties (Chart 1 ), which is even soluble in organic solvents, could be prepared by the reaction of silanetriol with $(\mathrm{MesCu})_{4}\left(\mathrm{Mes}=2,4,6-\mathrm{Me}_{3} \mathrm{C}_{6} \mathrm{H}_{2}\right)$. This copper siloxane cluster is active for the Ullmann-Goldberg-type $\mathrm{C}-\mathrm{N}$ coupling reaction, ${ }^{2}$ and can serve as a structural and functional model for silica-supported copper (pre)catalysts. In order to better understand the structurereactivity relationships of $\mathrm{Cu}-\mathrm{O}-\mathrm{Si}$ systems for various $\mathrm{Cu}$-based chemical transformations, the synthesis of other types of $\mathrm{Cu}-\mathrm{O}-\mathrm{Si}$ containing compounds as structural and functional models for metallated terminal $\mathrm{OH}$ groups of silica surfaces is desired.

Organic silanols have been reported to form well defined $\mathrm{M}-\mathrm{O}-\mathrm{Si}$ type compounds including silanediols, disiloxane-1,3-diols, silanetriols, trisiloxane-diol and silsesquioxane-triols (Chart 1). ${ }^{1 a, b, 3,4}$ As possible intermediates involved in silica synthesis through hydrolysis of suitable silicon(Iv) starting materials under acidic conditions, silicic acids, $\mathrm{SiO}_{x}(\mathrm{OH})_{4-2 x}$, have not received much attention as precursors for the selective synthesis of $\mathrm{M}-\mathrm{O}-\mathrm{Si}$ compounds owing to their elusive nature. Likewise, organic silanoic acids $\mathrm{RSi}(=\mathrm{O}) \mathrm{OH}$,

Technische Universität Berlin, Department of Chemistry, Metalorganics and Inorganic Materials, Sekr. C2, Strasse des 17. Juni 135, 10623 Berlin, Germany. E-mail: Matthias.driess@tu-berlin.de; Fax: +49 30-314-29732

$\uparrow$ Electronic supplementary information (ESI) available: Experimental details and crystal data and structure refinement for 3-5. CCDC 921657-921659. For crystallographic data in CIF or other electronic format see DOI: $10.1039 / \mathrm{c} 3 \mathrm{cc} 41965 \mathrm{~g}$

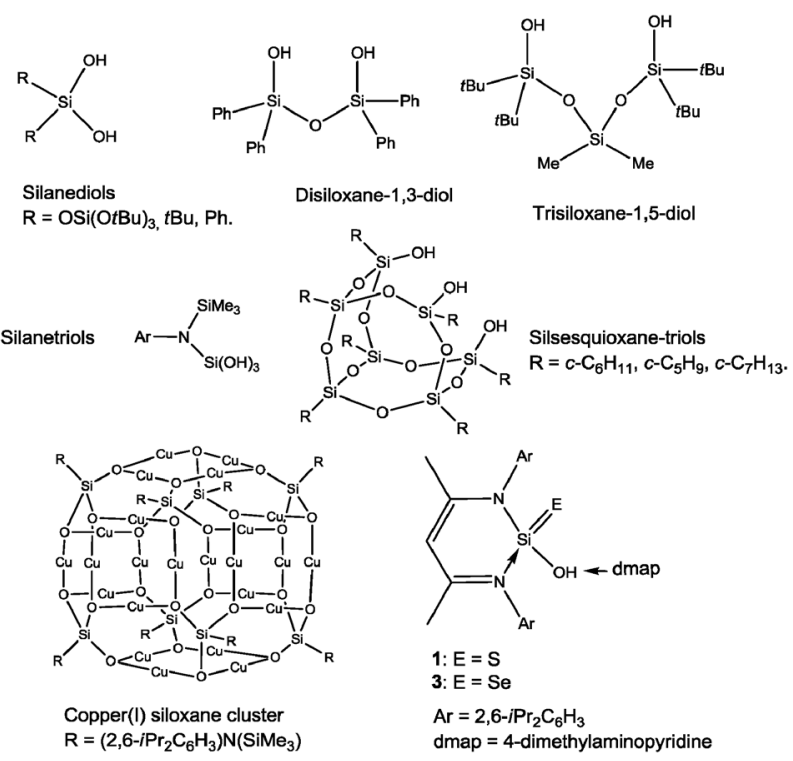

Chart 1

the silicon analogues of carboxylic acids, represent elusive species which could only be studied at liquid nitrogen temperatures because of the presence of the highly polarized $\mathrm{Si}=\mathrm{O}$ subunit which can undergo facile isomerisation or intermolecular head-to-tail polymerisation. ${ }^{5}$ Recently, we reported the synthesis of the first isolable silanoic acid-base adducts, including the thiosilanoic system $\mathrm{LSi}(=\mathrm{S}) \mathrm{OH}(\mathrm{dmap}) \mathbf{1}\left(\mathrm{L}=\mathrm{CH}[\mathrm{C}(\mathrm{Me}) \mathrm{NAr}]_{2}, \mathrm{Ar}=2,6-\mathrm{iPr}_{2} \mathrm{C}_{6} \mathrm{H}_{3}\right.$, dmap = 4-dimethylaminopyridine) which is stabilised via hydrogen bonding to the pyridine $\mathrm{N}$ atom of dmap (Chart 1$).{ }^{6}$ With these compounds in hand it became possible to employ 1 as a building block for $\mathrm{Si}(=\mathrm{S})-$ $\mathrm{O}-\mathrm{M}$ formation. Accordingly, we reported the formation and reactivity of an isolable monomeric $\mathrm{Si}(=\mathrm{S})-\mathrm{O}-\mathrm{Mn}(\mathrm{II})$ complex. ${ }^{7}$ Herein, we report the unexpectedly facile synthesis of the first isolable selenosilanoic acid-base adduct $\mathrm{LSi}(=\mathrm{Se}) \mathrm{OH}($ dmap) 3 (Chart 1 ), and the $\mathrm{Cu}$-metallation reactions of $\mathbf{1}$ and $\mathbf{3}$ with $(\mathrm{MesCu})_{4}$ to give the novel dimeric $\mathrm{LSi}(=\mathrm{E}) \mathrm{OCu}$ complexes $4(\mathrm{E}=\mathrm{S})$ and $5(\mathrm{E}=\mathrm{Se})$ with unprecedented intermolecular $\mathrm{Si}=\mathrm{E} \rightarrow \mathrm{Cu}-\mathrm{O}-\mathrm{Si}$ coordination modes. In addition, their ability to serve as efficient pre-catalysts 


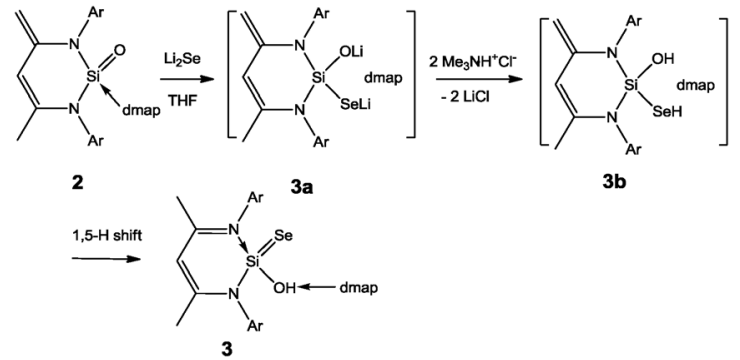

Scheme 1 Synthesis of compound 3.

in the aziridation of a $\mathrm{C}=\mathrm{C}$ bond with $\mathrm{PhI}=\mathrm{N}(\mathrm{Ts})$ has been demonstrated.

The thiosilanoic acid-base complex $\mathbf{1}$ is accessible from the reaction of the corresponding stable silanone complex $\mathrm{L}^{\prime} \mathrm{Si}(=\mathrm{O})$ (dmap) $2\left(\mathrm{~L}^{\prime}=\mathrm{CH}\left[\mathrm{C}(\mathrm{Me})\left(\mathrm{C}=\mathrm{CH}_{2}\right)\right]\left(\mathrm{NAr}_{2}\right), \mathrm{Ar}=2,6-\mathrm{Pr}_{2} \mathrm{C}_{6} \mathrm{H}_{3}\right)$ with $\mathrm{H}_{2} \mathrm{~S}$ at ambient temperature. Considering the toxicity of $\mathrm{H}_{2} \mathrm{Se}$, we attempted to synthesize the selenium congener of $\mathbf{1}$ with dilithium selenide as a selenium source, which can be obtained from the reaction of elemental selenium with lithium triethylhydridoborate in THF. ${ }^{8}$ Treatment of the in situ prepared dilithium selenide with one equivalent of 2 in THF at $-78{ }^{\circ} \mathrm{C}$, followed by protonation with two molar equivalents of trimethylammonium chloride, leads to a clear yellow solution, from which compound 3 could be isolated in the form of yellow crystals in $75 \%$ yield (Scheme 1).

The strikingly stable compound 3 has very similar solubility properties to 1. It is soluble in toluene, THF, chloroform, dichloromethane, marginally soluble in benzene but insoluble in $n$-hexane. It was fully characterised using multinuclear NMR spectroscopy, elemental analysis, mass spectrometry and IR spectroscopy, as well as single-crystal X-ray diffraction analysis. The high resolution electrospray ionization mass spectrometry (ESI-MS) shows the molecular ion peak at $m / z 665.3138[\mathrm{LSi}(=\mathrm{Se}) \mathrm{OH}(\mathrm{DMAP})+\mathrm{H}]^{+}$as the base signal. In the ${ }^{1} \mathrm{H}$ NMR spectrum in $\mathrm{CDCl}_{3}$, the chemical shift of the ring proton in the $\gamma$-position of the $\beta$-diketiminate $\mathrm{L}$ is observed at $\delta=5.73 \mathrm{ppm}$. This chemical shift is comparable to that observed for $\mathbf{1}(\delta=5.71 \mathrm{ppm})$. The proton of the $\mathrm{OH}$ group resonates at $\delta=6.42 \mathrm{ppm}$ in the same region as the proton resonance signals for the pyridine moiety of dmap. The ${ }^{29} \mathrm{Si}\left\{{ }^{1} \mathrm{H}\right\}$ resonance signal of 3 in $\mathrm{CDCl}_{3}$ at $\delta=-25.5 \mathrm{ppm}$ is low-field shifted compared to that of $\mathbf{1}(\delta=-30.0 \mathrm{ppm})$, while its ${ }^{77} \mathrm{Se}\left\{{ }^{1} \mathrm{H}\right\}$ NMR spectrum exhibits a singlet at $\delta=-545.2 \mathrm{ppm}$, which is up-field shifted compared to those of the related selenosilanoic silylester diastereomers $(\delta=-384.8$ and $-401.3 \mathrm{ppm}){ }^{9}{ }^{9}$

The molecular structure of compound 3 is depicted in Fig. 1. It crystallizes in the triclinic space group $P \overline{1}$ with one $n$-hexane molecule lying about an inversion center. It is isotypic with $\mathbf{1}$, with one dmap ligand connected to the selenosilanoic acid moiety through an $\mathrm{O}-\mathrm{H} \cdots \mathrm{N}$ hydrogen bond. The Si1-O1 bond length of $1.619(2) \AA$ is comparable to that of 1 (1.620(2) $\AA$ ), whereas the $\mathrm{Si}(1)-\mathrm{Se}(1)$ bond distance of $2.1348(7) \AA$ is close to the $\mathrm{Si}=\mathrm{Se}$ distance of a related selenosilanoic silyl ester $(2.117(1) \AA ̊) .{ }^{9}$ As expected, other metric parameters of $\mathbf{3}$ are akin to those of $\mathbf{1}$.

Both compounds $\mathbf{1}$ and $\mathbf{3}$ were allowed to react with $(\mathrm{MesCu})_{4}$ (Mes = 2,4,6-trimethylphenyl) in the hope of producing the corresponding $\mathrm{Cu}(\mathrm{I})$ complexes $\mathbf{4}$ and $\mathbf{5}$, respectively. $(\mathrm{MesCu})_{4}$ is

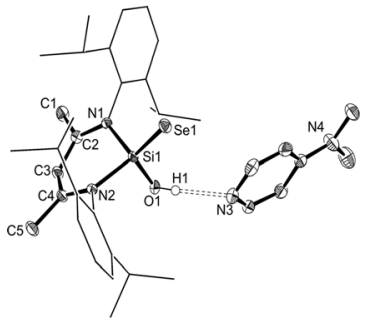

Fig. 1 Molecular structure of compound 3 in the solid state with the $50 \%$ probability level for the core structure. Hydrogen atoms (except for $\mathrm{H} 1$ ) and the $n$-hexane molecules are omitted for the sake of clarity.
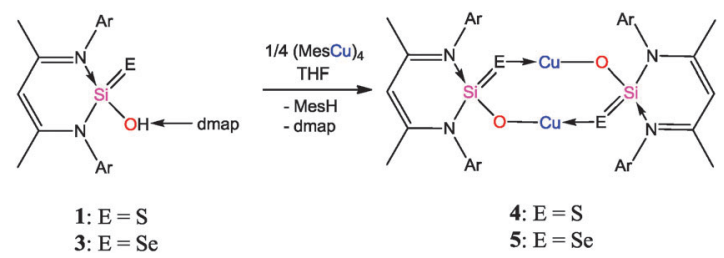

Scheme 2 Syntheses of the $\mathrm{Cu}(\mathrm{I})$ complexes $\mathbf{4}$ and $\mathbf{5}$.

known to serve as a smooth reagent for preparing $\mathrm{Cu}(\mathrm{I})$ complexes by deprotonation of amines and silanols. ${ }^{2,3,10}$

Accordingly, the reaction of compound 1 with $\frac{1}{4}$ molar equivalent of $(\mathrm{MesCu})_{4}$ was carried out in THF at $-20{ }^{\circ} \mathrm{C}$. The ${ }^{1} \mathrm{H}$ NMR spectrum of the resulting reaction mixture already shows the absence of the resonance signals of the $\mathrm{OH}$ group of $\mathbf{1}$ and those of $(\mathrm{MesCu})_{4}$ with concomitant liberation of dmap, indicating that the metallation of $\mathbf{1}$ was successful. Indeed, the desired compound 4 could be isolated from the reaction mixture as yellow crystals in $85 \%$ yield (Scheme 2). Single crystals of 4 suitable for X-ray diffraction analysis could be obtained in toluene solutions at $0{ }^{\circ} \mathrm{C}$. The structure analysis revealed that the compound is a dimer with intermolecular $\mathrm{Si}=\mathrm{S} \rightarrow \mathrm{Cu}-\mathrm{O}-\mathrm{Si}$ interactions (Fig. 2). The compound possesses $C_{2}$ symmetry and consists of a planar eightmembered $\mathrm{Si}_{2} \mathrm{O}_{2} \mathrm{~S}_{2} \mathrm{Cu}_{2}$ ring with two trans-oriented $\beta$-diketiminato ligands $\mathrm{L}$. The $\mathrm{Cu}$ centres are linearly coordinated by one oxygen and a sulfur atom of the neighbouring $\mathrm{Si}=\mathrm{S}$ subunit. The $\mathrm{Cu}(1) \cdots \mathrm{Cu}(1 \mathrm{~A})$ distance of $2.8135(7) \AA$ suggests a weak $\mathrm{d}^{10} \cdots \mathrm{d}^{10}$ interaction in this molecule. ${ }^{11}$ The $\mathrm{Si}(1)-\mathrm{O}(1)$ distance of $1.568(2) \AA$ is significantly shorter than that in the precursor 1 (1.620(2) $\AA$ ), whereas the $\mathrm{Si}(1)-\mathrm{S}(1)$ bond length $(2.0609(9))$ is longer than that a)

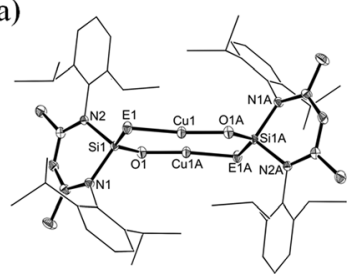

b)

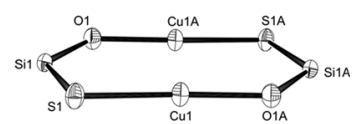

Fig. 2 (a) Molecular structures of compounds $4(E=S)$ and $\mathbf{5}(E=S e)$ in the solid state with the $50 \%$ probability level for the core structure. Hydrogen atoms and the toluene molecules are omitted for the sake of clarity. Operation symmetry for all atoms labelled " $\mathrm{A}$ ": $-x+3 / 2,-y+1 / 2,-z(4) ;-x+2,-y,-z$ (5); (b) representation of the eight-membered planar $\mathrm{Si}_{2} \mathrm{O}_{2} \mathrm{~S}_{2} \mathrm{Cu}_{2}$ ring without substituents at silicon atoms. 


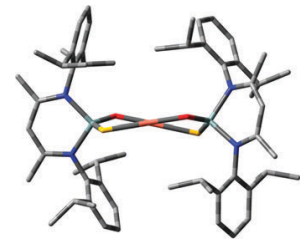

Fig. 3 Optimized structure for the proposed stereoisomer 4b. Hydrogen atoms are omitted for the sake of clarity.

observed in 1 (1.993(1) ̊̊), suggesting carboxylate-like $\pi$-conjugation in the SiSO moiety. ${ }^{12}$

The composition of $\mathbf{4}$ has been confirmed by multinuclear NMR spectroscopy, elemental analysis and IR spectroscopy. The solubility of 4 is similar to that of precursor 1. Unexpectedly, two sets of resonances for the $\beta$-diketiminato ligand $L$ appear in the ${ }^{1} \mathrm{H} N \mathrm{NR}$ spectrum with a ratio of $1: 0.62$ as indicated by the integrals of the resonances from the ring proton in the $\gamma$-position of $\mathrm{L}$ at $\delta=5.55$ and 5.49 ppm, respectively. Accordingly, the ${ }^{29} \mathrm{Si}\left\{{ }^{1} \mathrm{H}\right\}$ NMR spectrum reveals two close signals at $\delta=-38.0$ and $-39.1 \mathrm{ppm}$, respectively. The two sets of resonances suggest the presence of two stereoisomers of $\mathbf{4}$ (4a and $\mathbf{4 b}$ ) in chloroform solutions. Indeed this is substantiated by the results obtained from diffusion ordered spectroscopy (DOSY) experiments, revealing identical diffusion coefficients for these two species (see ESI $\dagger$ ) and thus the same molecular size and composition, respectively. In other words, dissociation of $\mathbf{4}$ in chloroform solutions can be excluded. As expected, the two stereoisomers can be interconverted as shown using variable ${ }^{1} \mathrm{H}$ NMR spectroscopy. Cooling of a $\mathrm{CDCl}_{3}$ solution of 4 to $230 \mathrm{~K}$ changes the ratio of signal sets of $4 \mathbf{a}$ and $\mathbf{4 b}$ from $1: 0.62$ at ambient temperature to $1: 0.42$ (see $\mathrm{ESI} \dagger$ ). In the solid state ${ }^{29} \mathrm{Si} \mathrm{NMR}$ spectrum of $\mathbf{4}$ in crystalline form, there is only one resonance signal at $\delta=-41.6 \mathrm{ppm}$, whereas in the spectrum of the fine powder two signals are observed $(\delta=-41.6 \mathrm{ppm}$ and $-38.7 \mathrm{ppm})$ (see ESI $\dagger$ ), this suggests that 4a holds a structure as shown in Fig. 2 with two ligands $\mathrm{L}$ in the trans-position. We inferred that the other stereoisomer $\mathbf{4 b}$ preserves the $C_{2}$ symmetry of $4 \mathrm{a}$ but the two ligands $\mathrm{L}$ are now cis-oriented. However, this is ruled out by the results of DFT calculations, which revealed that the proposed cis isomer is least favoured. Instead the DFT calculations suggest a twisted $\mathrm{Si}_{2} \mathrm{O}_{2} \mathrm{~S}_{2} \mathrm{Cu}_{2}$ core structure also with $C_{2}$ symmetry as a stereoisomer which is only $5.5 \mathrm{~kJ} \mathrm{~mol}^{-1}$ less stable than $4 \mathrm{a}$ (Fig. 3 and ESI $\dagger$ ).

Similar to the synthesis of $\mathbf{4}$, compound 5 could be obtained by the reaction of 3 with $(\mathrm{MesCu})_{4}$ in THF (Scheme 2). Compound 5 has been fully characterized by multinuclear NMR spectroscopy, elemental analysis, IR and mass spectroscopy, and X-ray crystallography. Akin to the situation of $\mathbf{4}$, there are two stereoisomers present in $\mathrm{CDCl}_{3}$ solutions as shown by the ${ }^{1} \mathrm{H},{ }^{13} \mathrm{C},{ }^{29} \mathrm{Si} \mathrm{NMR}$ spectra as well as ${ }^{1} \mathrm{H}$-DOSY experiments (see ESI $\dagger$ ).

Single-crystals of $\mathbf{5}$ in the triclinic space group $P \overline{1}$ could be obtained in toluene solutions. The X-ray diffraction analysis revealed that 5 and $\mathbf{4}$ are isotypic (Fig. 2). Akin to the structure of $\mathbf{4}$, compound 5 is a dinuclear copper(I) complex with both copper centers coordinated by $\mathrm{O}$ and Se atoms. A linear geometry of the O-Cu-Se connection with an angle of 172.07(7) ${ }^{\circ}$ is observed. The $\mathrm{Cu}(1) \cdots \mathrm{Cu}(1 \mathrm{~A})$ bond distance of $2.9271(8) \AA$ is slightly longer than that in compound $4(2.8135(7) \AA)$. This can be explained by the longer Si-Se distance (2.2011(9) ̊) compared to that of the Si-S bond $(2.0609(9) \AA)$ in 4 .

It has been shown that $\mathrm{Cu}(\mathrm{I})$ complexes can be efficiently applied as pre-catalysts in metal-catalyzed nitrene-transfer reactions if the $\mathrm{Cu}(\mathrm{I})$ centre is efficiently chelate coordinated. ${ }^{13}$ In a preliminary study the catalytic ability of compounds $\mathbf{4}$ and $\mathbf{5}$ in the nitrenetransfer reaction (aziridation) of a $\mathrm{C}=\mathrm{C}$ bond has been evaluated. The catalytic reactions were carried out by using styrene and $\mathrm{PhI}=\mathrm{N}(\mathrm{Ts})(\mathrm{Ts}=$ tosyl $)$ as a nitrene source in the presence of $2.5 \mathrm{~mol} \%$ of 4 and 5, respectively, in $\mathrm{CH}_{2} \mathrm{Cl}_{2}$ at ambient temperature. The resulting yields of the $N$-tosyl-2-phenylaziridine product [ $85 \%$ (4) and $87 \%(5)]$ are similar to a reported result. ${ }^{13 a}$ It is generally considered that a $\mathrm{Cu}(\mathrm{I})$-nitrene species is the active component for the aziridination reaction. ${ }^{13 b}$ Thus, it is reasonable to assume that the dimeric $\mathrm{Cu}(\mathrm{I})$ complexes react initially with $\mathrm{PhI}=\mathrm{N}(\mathrm{Ts})$ to form the corresponding $\mathrm{Cu}(\mathrm{I})$-nitrene intermediates, which are capable of facile nitrene-transfer to the $\mathrm{C}=\mathrm{C}$ bond of styrene.

In summary, using dilithium selenide as a selenium source, the first isolable selenosilanoic acid-base adduct 3 has been synthesized which is isostructural with the thiosilanoic acid-base adduct $\mathbf{1}$. Facile reaction of $\mathbf{1}$ and $\mathbf{3}$ with $\frac{1}{4}$ molar equivalents of $(\mathrm{MesCu})_{4}$ led to the unprecedented dimeric copper(I) complexes 4 and 5. Both complexes exist in two stereoisomeric forms in chloroform solutions and verify the novel $\mathrm{Si}=\mathrm{E} \rightarrow \mathrm{Cu}-\mathrm{O}-\mathrm{Si}$ structural motif in $\mathrm{Cu}(\mathrm{I})$ siloxane chemistry. In addition, compounds $\mathbf{4}$ and $\mathbf{5}$ can act as reliable pre-catalysts in aziridination of styrene with $\mathrm{PhI}=\mathrm{N}(\mathrm{Ts})$.

\section{Notes and references}

1 (a) R. Murugavel, A. Voigt, M. G. Walawalkar and H. W. Roesky, Chem. Rev., 1996, 96, 2205-2236; (b) R. Murugavel, V. Chandrasekhar and H. W. Roesky, Acc. Chem. Res., 1996, 29, 183-189; (c) N. Winkhofer, A. Voigt, H. Dorn, H. W. Roesky, A. Steiner, D. Stalke and A. Reller, Angew. Chem., Int. Ed. Engl., 1994, 33, 1352-1354; (d) H. C. L. Abbenhuis, Chem.-Eur. J., 2000, 6, 25-32; (e) K. L. Fujdala, I. J. Drake, A. T. Bell and T. D. Tilley, J. Am. Chem. Soc., 2004, 126, 10864-10866.

2 G. Tan, Y. Yang, C. Chu, H. Zhu and H. W. Roesky, J. Am. Chem. Soc., 2010, 132, 12231-12233.

3 F. Schax, C. Limberg and C. Mügge, Eur. J. Inorg. Chem., 2012, 4661-4668.

4 (a) V. Lorenz, A. Fischer, K. Jacob, W. Brueser and F. T. Edelmann, Chem.-Eur. J., 2001, 7, 848-857; (b) V. Lorenz, S. Gießmann, Y. K. Gun'ko, A. K. Fischer, J. W. Gilje and F. T. Edelmann, Angew. Chem., Int. Ed., 2004, 43, 4603-4606; (c) V. Lorenz, A. Fischer, K. Jacob, W. Brueser, T. Gelbrich, P. G. Jones and F. T. Edelmann, Chem. Commun., 1998, 2217-2218.

5 (a) C. A. Arrington, R. West and J. Michl, J. Am. Chem. Soc., 1983, 105, 6176-6177; (b) R. Withnall and L. Andrews, J. Am. Chem. Soc., 1985, 107, 2567-2568.

6 Y. Xiong, S. Yao and M. Driess, Angew. Chem., Int. Ed., 2010, 49, 6642-6645.

7 S. Yao, Y. Xiong and M. Driess, Chem.-Eur. J., 2012, 18, 11356-11361. 8 U. Herzog, H. Lange, H. Borrmann, B. Walfort and H. Lang, J. Organomet. Chem., 2004, 689, 4909-4916.

9 S. Yao, Y. Xiong, M. Brym and M. Driess, Chem.-Asian. J., 2008, 3, 113-118.

10 (a) G. Tan and H. Zhu, Inorg. Chem., 2011, 50, 6979-6986; (b) M. Stollenz and F. Meyer, Organometallics, 2012, 31, 7708-7727.

11 (a) P. K. Mehrotra and R. Hoffmann, Inorg. Chem., 1978, 17, 2187-2189; (b) K. M. Merz Jr. and R. Hoffmann, Inorg. Chem., 1988, 27, 2120-2127.

12 (a) R. D. Mounts, T. Ogura and Q. Fernando, Inorg. Chem., 1974, 13, 802-805; (b) A. S. Filatov, O. Hietsoi, Y. Sevryugina, N. N. Gerasimchuk and M. A. Petrukhina, Inorg. Chem., 2010, 49, 1626-1633.

13 (a) P. J. Pérez, M. Brookhart and J. L. Templeton, Organometallics, 1993, 12, 261-262; (b) Y. M. Badiei, A. Krishnaswamy, M. M. Melzer and T. H. Warren, J. Am. Chem. Soc., 2006, 128, 15056-15057. 